See Article page e163.

\section{Commentary: Two clinical solutions and many molecular options for aortic valve stenosis}

\author{
Ari A. Mennander, MD, PhD
}

Aortic valve replacement either with or without cardiopulmonary bypass necessitates much from the patient and the surgical team. Surgical intervention requires technical expertise, hospitalization, and must be tailored according to comorbidities. The current 2 options to treat the patient with severe aortic valve stenosis include implantation of a prosthesis after either radical extraction or crunching of the lesions against the more or less diseased aorta. What if the entire aortic valve stenosis was prevented even from developing?

The current study by Zhou and colleagues ${ }^{1}$ demonstrates that methyltransferase-like 3 (METTL3) participates in aortic valve stenosis by inhibiting twist-related protein 1 (TWIST1) while interacting with $\mathrm{N}^{6}$-methyladenosine (m6A). Human interstitial cells from both healthy and calcified aortic valves were investigated for METTL3. METTL3 was upregulated in calcific aortic valves and acted as a positive regulator of osteogenic differentiation of the aortic valve interstitial cells, as shown by increased alkaline phosphatase activity, calcified nodule formation, and the protein levels of 3 osteogenic-specific markers, namely Runx2, osterix, and osteocalcin. Demonstrative figures are presented. The study adheres to power calculation with a representative number of samples.

METTL3-mediated m6A modification has a key role in human cardiovascular diseases, such as cardiac hypertrophy, heart failure, and coronary artery disease. ${ }^{2-4}$ The study investigated several important regulators of aortic valve calcification, namely TWIST1, serotonin 2B receptor, klotho, histone deacetylase 6 , calponin 2, cyclooxygenase 2 , and dipeptidyl peptidase-4; only TWIST1 was decreased at the gene and protein levels upon increased METTL3 expression. The role of TWIST

From Tampere University Heart Hospital and Tampere University, Tampere, Finland. Disclosures: Author has nothing to disclose with regard to commercial support.

Received for publication Oct 27, 2019; revisions received Oct 27, 2019; accepted for publication Oct 27, 2019; available ahead of print Nov 20, 2019.

Address for reprints: Ari A. Mennander, MD, PhD, Tampere University Heart Hospital, SDSKIR, PL 2000, Tampere, Finland (E-mail: ari.mennander@sydansairaala. fi).

J Thorac Cardiovasc Surg 2021;161:e187-8

0022-5223/\$36.00

Copyright () 2019 by The American Association for Thoracic Surgery

https://doi.org/10.1016/j.jtcvs.2019.10.167

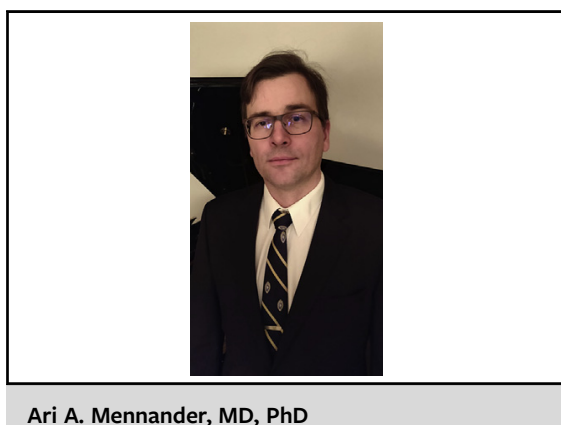

Ari A. Mennander, MD, PhD

CENTRAL MESSAGE

Experimental research on epige-

netics, such as METTL3mediated m6A modification, may

open a vast field of still-

uncovered possibilities to

unravel clinically unsolved

dilemmas

in the differentiation of aortic valve is well-established, but TWIST1 has also been reported to be modulated by other pathways. ${ }^{5}$

What can the clinician learn from this study? Presumably, the METTL3-mediated m6A modification pathway needs to be inhibited before any onset of aortic valve calcification. Maybe the inhibition of the pathway could be done using an Adeno-associated virus vector carrying the METTL3-like inhibitor ${ }^{1}$; gene therapy with Adenoassociated virus vectors has already been successful in a few previous experimental studies. ${ }^{6,7}$ The promising results warrant further experimental studies before the theory is safely considered to be applied into a translational protocol aiming to prevent aortic valve stenosis. It is still unknown whether the specific inhibition of the molecular METTL3-mediated m6A modification pathway is sufficient to abolish the osteogenic-like process leading to aortic valve stenosis. The challenge is not to completely abolish METTL3 as this, ironically, may lead to heart failure through acceleration of some altering pathways. ${ }^{8}$ There may be a threshold of METTL3 inhibition that should not be reached not to evoke compensatory pathways that could instead lead to undesired outcome.

Aortic valve interstitial cell deterioration is an end-stage phenomenon of a diverse of cellular pathways leading to aortic valve stenosis. Identifying different molecular pathways leading to calcification of the aortic valve interstitial 
cells aids to perceive a comprehensive molecular network explaining the mosaic-like pathogenesis of the aortic valve disease; experimental research on epigenetics, such as METTL3-mediated m6A modification, may open a vast field of still-uncovered possibilities to unravel clinically unsolved dilemmas.

\section{References}

1. Zhou T, Han D, Liu J, Shi J, Zhu P, Wang Y, et al. Factors influencing osteogenic differentiation of human aortic valve interstitial cells. J Thorac Cardiovasc Surg. 2021;161:e163-85.

2. Dorn LE, Lasman L, Chen J, Xu X, Hund TJ, Medvedovic M, et al. The $\mathrm{N}^{6}$ methyladenosine mRNA methylase METTL3 controls cardiac homeostasis and hypertrophy. Circulation. 2019;139:533-45.
3. Mathiyalagan P, Adamiak M, Mayourian J, Sassi Y, Liang Y, Agarwal N, et al. FTO-dependent $\mathrm{N}^{6}$-methyladenosine regulates cardiac function during remodeling and repair. Circulation. 2019;139:518-32.

4. Mo X-B, Lei S-F, Zhang Y-H, Zhang H. Detection of m6A-associated SNPs as potential functional variants for coronary artery disease. Epigenomics. 2018;10: 1279-87.

5. Zhu L, Xi PW, Li XX, Sun X, Zhou WB, Xia TS, et al. The RNA binding protein RBMS3 inhibits the metastasis of breast cancer by regulating Twist 1 expression. $J$ Exp Clin Cancer Res. 2019;28:105-15.

6. Gabisonia K, Prosdocimo G, Aquaro GD, Carlucci L, Zentilin L, Secco I, et al. MicroRNA therapy stimulates uncontrolled cardiac repair after myocardial infarction in pigs. Nature. 2019;569:418-22.

7. Naso MF, Tomkowicz B, Perry WL III, Strohl WR. Adeno-associated virus (AAV) as a vector for gene therapy. BioDrugs. 2017;31:317-34.

8. Pagiatakis C, Condorelli G. The RNA methylome blackboard. METTL3 and FTO, epigenetic writers and erasers regulating cardiac homeostasis through epitranscriptome modification. Circulation. 2019;139:546-8.

\section{Commentary: Aortic valve} calcification: A new story with a twist?

\author{
Igor E. Konstantinov, MD, PhD, FRACS,,$^{\mathrm{a}, \mathrm{b}, \mathrm{c}, \mathrm{d}}$ and \\ Yaroslav Y. Ivanov, MD, $\mathrm{PhD}^{\mathrm{a}}$
}

Aortic valve calcification (AVC) is considered a multifactorial disease involving a diverse spectrum of cellular and molecular mechanisms. ${ }^{1}$ Recently, it was hypothesized that valvular interstitial cells (VICs), which are prevalent in all layers of the aortic valve, may play an important role in $\mathrm{AVC}^{2}$ In particular, their differentiation into the osteoblast phenotype is a key pathogenetic mechanism of aortic valve osseous metaplasia with subsequent mineralization. Although many factors could contribute to the development of AVC, including but not limited to abnormal biomechanical forces, hypercholesterolemia and inflammation, ${ }^{3}$ factors triggering the osteoblastic differentiation of VICs have not been completely identified.

\footnotetext{
From the 'Royal Children's Hospital, Melbourne; 'Murdoch Children's Research Institute, Melbourne; ' University of Melbourne, Melbourne; and ${ }^{\mathrm{d}}$ Melbourne Children's Centre for Cardiovascular Genomics and Regenerative Medicine, Melbourne, Australia.

Disclosures: Authors have nothing to disclose with regard to commercial support.

Received for publication Oct 29, 2019; revisions received Oct 29, 2019; accepted for publication Nov 4, 2019; available ahead of print Nov 27, 2019.

Address for reprints: Igor E. Konstantinov, MD, PhD, FRACS, Royal Children's Hospital, Flemington Rd, Parkville, VIC 3052, Australia (E-mail: igor. konstantinov@rch.org.au).

J Thorac Cardiovasc Surg 2021;161:e188-9 0022-5223/ $\$ 36.00$

Crown Copyright (C) 2019 Published by Elsevier Inc. on behalf of The American Association for Thoracic Surgery

https://doi.org/10.1016/j.jtcvs.2019.11.025
}

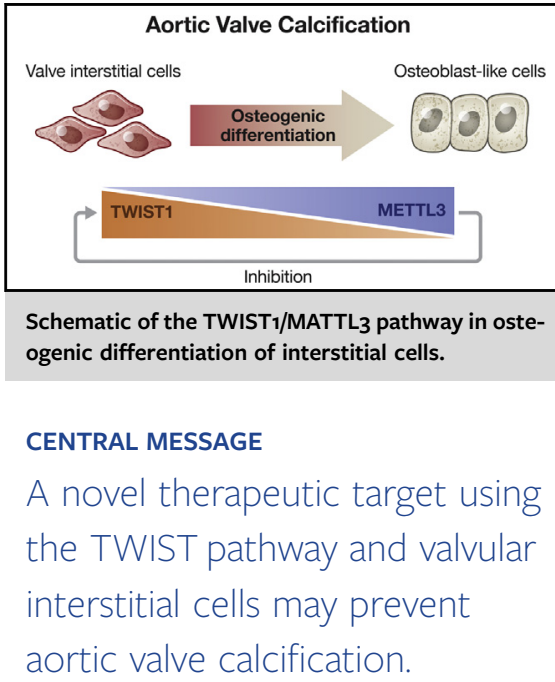

The methylation of N6-methyladenosine (m6A), an abundant nucleotide modification in eukaryotic RNA, is essential for multiple RNA processing events ${ }^{4}$ and, as was recently discovered, plays an important role in cardiomyocyte homeostasis. ${ }^{5}$ This process is accomplished via the methyltransferase complex, in which methyltransferaselike 3 (METTL3) plays a key role.

The interesting report by Zhou and colleagues ${ }^{6}$ in this issue of the Journal confirms that METTL3 is a positive regulator of VIC osteogenic differentiation in the setting of AVC. The osteogenic differentiation occurs via 